\title{
В. В. Колбанов*
}

Федеральное государственное бюджетное образовательное учреждение высшего образования «Первый Санкт-Петербургский государственный медицинский университет имени академика И. П. Павлова» Министерства здравоохранения Российской Федерации, Санкт-Петербург, Россия

\section{НАУЧНАЯ ШКОЛА АКАДЕМИКА Л. А. ОРБЕЛИ В ПЕТРОГРАДЕ - ЛЕНИНГРАДЕ (к столетию ее создания)}

\section{Резюме}

Поступияа в реgакцию 11.11.2020 г.; принята к печати 15.02.2021 г

Прослежены основные этапы становления, развития и распространения в Петрограде - Аенинграде научной школы академика $\lambda$. А. Орбели. Показано значение фундаментальных научных исследований этой школы в области физиологии для развития смежных областей медицины и биологии.

Ключевые слова: научная школа, Первый Петроградский медицинский институт, Военно-медицинская академия, кафедры физиологии, преподаватели, студенты

Аля цитирования: Колбанов В. В. Научная школа академика $\lambda$. А. Орбели в Петрограде - Аенинграде (к столетию ее создания). Ученые записки СПбГМУ им. акаg. И. П. Павлова. 2020;27(4):9 - 13. DOI: 10.24884/1607-4181-2020-27-4-9-13.

* Автор для связи: Владимир Васильевич Колбанов, ФГБОУ ВО ПСПбГМУ им. И. П. Павлова Минздрава России, 197022, Россия, Санкт-Петербург, ул. Аьва Толстого, А. 6-8. E-mail: kolbanovv@bk.ru.

\author{
Vladimir V. Kolbanov* \\ Pavlov University, Saint Petersburg, Russia
}

\section{SCIENTIFIC SCHOOL OF ACADEMICIAN L. A. ORBELIIN PETROGRAD - LENINGRAD (to hundredth anniversary of its creation)}

\section{Summary}

Received 11.11.2020; accepted 15.02.2021

Basic stages of creation, development and spreading of academician L. A. Orbeli scientific school at Petrograd - Leningrad were traced. Significance of main scientific researches of this school in the physiology for the development of adjacent areas of medicine and biology was shown.

Keywords: scientific school, First Petrograd medical Institute, Military Medical Academy, departments of physiology, teachers, students

For citation: Kolbanov V. V. Scientific school of academician L. A. Orbeli in Petrograd - Leningrad (to hundredth anniversary of its creation). The Scientific Notes of Pavlov University. 2020;27(4):9 - 13. (In Russ.). DOI: 10.24884/1607-4181-2020-27-4-9-13.

*Corresponding author: Vladimir V. Kolbanov, Pavlov University, 6-8, L'va Tolstogo str., Saint Petersburg, 197022, Russia. E-mail: kolbanovv@bk.ru.

\section{ВВЕДЕНИЕ}

Год 1920-й. Завершился изрядно затянувшийся конкурс на заведование кафедрой физиологии Первого Петроградского медицинского института. После гибели первого заведующего, профессора В. И. Вартанова, на кафедре не осталось его пре- емника, а претендентов на эту должность оказалось четверо. По решению конкурсной комиссии заведование принял доцент Военно-медицинской академии, дивизионный врач Леон Абгарович Орбели. В России шла Гражданская война, и тогдашние законы допускали совмещение многих обязанностей 
одним человеком по причине дефицита хорошо подготовленных специалистов. А. А. Орбели, один из учеников академика И. П. Павлова, оказался именно таким специалистом, способным возглавить коллектив преподавателей и исследователей. Несмотря на молодой возраст, кроме достижений в исследовательской работе, Леон Абгарович к этому времени имел еще и значительный педагогический опыт, накопленный в ВМА и в Естественно-научном институте имени П. Ф. Аесгафта.

\section{РЕОРГАНИЗАЦИЯ РАБОТЫ КАФЕДРЫ ФИЗИОЛОГИИ ПЕРВОГО ПЕТРОГРАДСКОГО МЕДИЦИНСКОГО ИНСТИТУТА}

Первой и неотложной проблемой на новом месте службы $\lambda$. А. Орбели оказалась организация учебного процесса. Штат кафедры физиологии был недостаточным для работы с большим числом студентов. Например, в 1920/21 учебном году на кафедре проходили обучение 552 студента, а в 1921/22 и 1922/23 учебные годы - по 800 с лишним человек [1].

Из прежних сотрудников кафедры достаточно подготовленными помощниками заведующему оказались только двое - В. В. Савич, приват-доцент, «староста павловской школы», и преподаватель А. В. Тонких, окончившая Женский медицинский институт в 1914 г. Аекционный курс вели два лектора. Аве лекции в неделю (большинство разделов курса) читал $\Lambda$. А. Орбели, одну лекцию в неделю (разделы эндокринологии и обмена веществ) В. В. Савич. Хотя посещение лекций в те годы не было обязательным, но лекции Орбели всегда привлекали большое число слушателей благодаря интересному и понятному изложению. В начале 1920-х гг. практические занятия на кафедре вели старший ассистент А. В. Тонких (с 1925 г. - приват-доцент), ассистент $\Lambda$. М. Рабинкова и препаратор Е. Н. Сперанская. Аефицит преподавателей частично компенсировался наличием пособия («задачника»), подготовленного И. С. Цитовичем в 1913 г. Надобность в более полном пособии к практическим занятиям вынудила привлечь к этой работе наиболее активных студентов-старшекурсников. Наряду со штатными сотрудниками кафедры, с 1922 г. помощь в учебной работе стали оказывать студенты-третьекурсники: сначала А. Г. Гинецинский и А. А. Ющенко, затем - . Г. Аейбсон, Г. В. Гершуни и др. К учебной и экспериментальной работе студенты допускались только после сgачи экзамена по физиологии. Каждому из начинающих исследователей Леон Абгарович поручал какую-нибудь тему, с каждым подолгу беседовал, объясняя ее научное значение, каждому помогал в освоении подчас сложной методики эксперимента.

Эти усилия завершились созданием в 1930 г. учебника-практикума по фризиологии, написанного выпускниками Института А. Г. Гинецинским и А. Г. Аейбсоном под редакцией $А$. А. Орбели.

В 1924 г. В. В. Савич покинул кафедру 1-го Медицинского института в связи с избранием на должность профессора Ветеринарного института, но к этому времени кафедра $\lambda$. А. Орбели пополнилась новыми сотрудниками из числа выпускников Института.

Вторая проблема, обусловленная нехваткой научно-педагогических кадров, - это подготовка аспирантов. Первыми аспирантами $\curlywedge$. А. Орбели стали А. А. Ющенко, Г. В. Гершуни, А. А. Волохов, А. Т. Худорожева, С. И. Гальперин, Н. В. Раева, Ф. А. Василенко. Естественно, аспиранты по мере готовности включались в обеспечение учебного процесса [2]. Штатное расписание Института в те годы не позволяло оставлять выпускников аспирантуры на кафедре, но все они были востребованы в других организациях. Позже, даже без оплаты труда, некоторые из них оказывали посильную помощь в учебном процессе кафедры физиологии.

В своих воспоминаниях о научном руководителе $\lambda$. А. Фирсов отметил существенное требование ᄉ. А. Орбели к аспирантской подготовке: «Только мы, орбелевские аспиранты, должны были в виде отдельного предмета по кандидатскому минимуму сдавать так называемые экспериментальные мастерские. Навыкам работы с паяльником, с газовой горелкой и стеклом, работе на токарном и сверлильном станке Аеон Абгарович придавал большое значение» [3, с. 155]. На фротоснимках фризиологических коллективов Института им. Лесгафта (1927) и Ленинградского медицинского института (1928) заметно присутствие отдельных лиц там и там. Это не случайность, а признак единства сообщества учеников $\lambda$. А. Орбели, несмотря на межведомственные границы. В лаборатории Медицинского института, кроме собственных студентов, проводили экспериментальные исследования по личной инициативе студенты Института им. П. Ф. Аесгафта и слушатели Военно-медицинской академии.

В Военно-медицинской академии до 1925 г. ^. А. Орбели читал лекции по общей физиологии нервов и мышц, физиологии вегетативной нервной системы и органов чувств один раз в неделю. В остальные дни он вел работу в Первом $А М И$ и Институте им. П. Ф. Аесгафта, однако был основным помощником Павлова по руководству кафедрой. В те же годы он вел в Академии практические занятия, обязательные не для всех, а только для наиболее заинтересованных в изучении физиологии.

В 1925 г., когда И. П. Павлов покинул кафедру физиологии ВМА, по решению начальника Военно-санитарного управления РККА $\Lambda$. А. Орбели был назначен начальником кафедры физиологии без объявления конкурса.

В статусе начальника кафедры Аеон Абгарович вынужден был решать существенные организационные вопросы, свойственные всей тогдашней 
системе высшего образования в стране: выбор оптимального соотношения учебных часов между лекционными и практическими занятиями. Административным попыткам сократить объем теоретической подготовки и форсировать внедрение активно-группового обучения за счет сокращения лекционных часов $\lambda$. А. Орбели так же обоснованно и решительно возражал, как и в стенах Медицинского института. Павловскую традицию лекционных демонстраций Орбели сохранил как своеобразную форму приглашения к размышлению на заданную тему.

\section{УЧЕБНАЯ РАБОТА НА КАФЕДРЕ ФИЗИОЛОГИИ ВМА}

С 1925 г. началась учебная реформа в ВМА. На кафедре были введены обязательные практические занятия. Предполагалось, что это произойдет за счет уменьшения числа лекций, однако нововведение затянулось более чем на 20 лет по причине дефицита материальных средств и нехватки преподавателей. Преподавание физиологии, как и прежде, оставалось на III и IV семестрах. Из общего количества учебного времени (более 200 ч) доминировала лекционная нагрузка, оставляя для практических занятий 16 учебных часов при наличии на кафедре физиологии всего четырех преподавателей. Только в 1940/41 учебном году, когда число преподавателей удвоилось, появилась возможность увеличить численность практических занятий до 92 ч [4].

Великая Отечественная война на печальном опыте первых дней показала недостаточную практическую подготовленность выпускников медицинских вузов к оказанию медицинской помощи в реальных условиях. Устранение этого недостатка было достигнуто двумя путями.

На переломном этапе войны, в 1943/44 учебном году, когда в штате кафедры оказалось 13 преподавателей, в системе подготовки военных врачей количество часов практических занятий возросло AO 111.

В 1942 г., наряду с устранением дисбаланса в первичной подготовке врачей, в ВМА впервые были созданы два фракультета усовершенствования - командно-медицинский и лечебно-профилактический. В программу обоих этих факультетов вошли курсы лекций по физиологии, включавшие в себя ряд вопросов физиологии военного труда для командного факультета и вопросы регуляции вегетативных функций - Аля фракультета лечебнопрофрилактического.

Кроме общего курса, который читался по разделам всеми профессорами и доцентами кафедры, по отдельной программе читались лекции отдельным группам слушателей - терапевтам, хирургам, невропатологам и т. А. Примером такого рода программ может служить план для группы терапевтов на 1944/45 учебный год, который включал в себя 30 лекционных часов и 20 часов практических занятий, включавших в себя тематику нормальной и патологической физиологии [4].

\section{МЕТОДИЧЕСКОЕ ОБЕСПЕЧЕНИЕ УЧЕБНОГО ПРОЦЕССА В ВМА}

В 20-х и в начале 30-х гг. кафедра физиологии пользовалась переводными учебниками, затем учебниками под редакцией Е. Б. Бабского и под редакцией К. М. Быкова. В 1940 г. коллективом кафедры фризиологии ВМА было издано первое учебное пособие Аля практических занятий, а в 1947 г. - учебник физиологии А. Г. Гинецинского и А. В. Аебединского, явившийся наиболее полным и систематичным из учебников того времени. Наличие учебника и учебного пособия, специально приспособленных к особенностям лекционного и практического курсов, значительно способствовало улучшению педагогического процесса на кафедре.

Не менее существенными Аля обеспечения учебного процесса были публикации научной школы $\lambda$. А. Орбели, в том числе «Лекции по физиологии нервной системы» $\lambda$. А. Орбели, вышедшие тремя изданиями (1934, 1935 и 1938 г.), его же «Лекции по вопросам высшей нервной деятельности» (1945) и «Вопросы высшей нервной деятельности» (1949). Сюда же можно отнести печатные труды сотрудников кафедры по частным вопросам: лекции И. И. Голодова - «Влияние высоких концентраций $\mathrm{CO}_{2}$ на организм» (1946), А. И. Бронштейна - «Сенсибилизация органов чувств» (1946), А. В. Лебединского и Н. Г. Саввина - «О механизме возникновения неврогенных дистрофий» (1945), Б. А. Кравчинского - «Физиология почек» (1949). Кроме того, значительная часть научных работ кафедры физиологии отражена в издававшихся в разное время сборниках трудов Военномедицинской академии и в «Военно-санитарных сборниках» Академии наук СССР.

\section{СПЕЦИФИКА НАУЧНОЙ РАБОТЫ В ВМА}

Кафедра физиологии ВМА, как и аналогичные кафедры вузов системы здравоохранения России и СССР, несмотря на наличие большого научного потенциала, в 1920 - 1930-е гг. была плохо приспособлена к решению проблем повышения обороноспособности страны. Необходимость научной переориентации кафедры остро чувствовалась уже в 20-х гг., когда академия начала постепенно переходить от теоретических исследований к научным работам, направленным на обеспечение нужд медицинской службы армии, авиации и военноморского флота.

5 декабря 1925 г. совет ВМА постановил принять к разработке, в числе других, тему «Труд красноармейца», а 27 ноября 1927 г. руководителем отдела «Труд красноармейца и питание» плана научноисследовательской работы академии был назначен ^. А. Орбели. С этого времени в академии началась разработка вопросов физиологии военного труда. 
Концентрация усилий преподавателей кафедры на проблеме физиологии военного труда не мешала принимать самое широкое участие в разработке общетеоретических вопросов, выдвигаемых $\lambda$. А. Орбели: фризиология сердечно-сосудистой и дыхательной систем, терморегуляция, вегетативная нервная система, функции мозжечка, органы чувств и другие физиологические проблемы. Общеизвестны крупные достижения сотрудников кафедры в разработке этих вопросов в предвоенные годы.

В 1932 г. А. А. Орбели избран членом-корреспондентом, а в 1935 г. - действительным членом Академии наук СССР, в 1939 г. избран академиком-секретарем, в 1942 г. - вице-президентом АН СССР, в 1944 г. - действительным членом АМН СССР.

Начало Великой Отечественной войны заставило кафедру направить свои исследования на обслуживание нужд фронта. В условиях блокированного ленинграда под руководством М. П. Бресткина осуществлялась разработка режимов глубоководных спусков водолазов и готовились кадры инструкторов, разрабатывались режимы отбора и тренировки летного состава, а под руководством А. В. Аебединского проводились исследования, благодаря которым была осуществлена практическая маскировка кораблей Балтийского флота, оборонявших Аенинград.

Эвакуация Академии в Самарканд и частично в Москву создала затруднения в руководстве кафедрой, тем более что $\lambda$. А. Орбели вынужден был выполнять работы в Президиуме АН СССР в Казани и Москве.

С возвращением кафедры в Ленинград в 1944 г. была налажена нормальная научная и учебная работа. В последние годы войны и первые послевоенные годы увеличился штат кафедры, так как в эти годы академия превратилась в научный и педагогический центр военной медицины. Ведь все медицинские вузы страны были включены в процесс подготовки офицеров медицинской службы запаса.

В 1943 г. А. А. Орбели был назначен начальником ВМА и до 1950 г. руководство Академией осуществлял одновременно с руководством кафедрой.

За период 1925-1950 гг. под руководством Орбели 16 человек успешно прошли адъюнктскую подготовку, 13 из них (В. А. Винокуров, И. И. Голодов, Т. К. Ажаракьян, А. Г. Жиронкин, А. Т. Загорулько, Г. А. Комендантов, А. Г. Кузнецов, Г. И. Мильштейн, А. С. Мозжухин, М. А. Пивоваров, Н. Г. Саввин, М. И. Сапрохин, А. Г. СверАлов) защитили кандидатские диссертации, а трем (В. В. Стрельцову, С. М. Аионесову и С. И. Прикладовицкому) ученая степень кандидата наук присуждена по совокупности научных работ.

Многие из учеников $\Lambda$. А. Орбели впоследствии стали основоположниками своих научных школ.

За большие заслуги в развитии отечественной науки и в подготовке высококвалифицированных кадров $\curlywedge$. А. Орбели в 1945 г. было присвоено звание Героя Социалистического Труда.

\section{ВКЛАД Л. А. ОРБЕЛИ В РАЗВИТИЕ ФИЗИОЛОГИЧЕСКОЙ НАУКИ В РОССИИ}

С момента создания Естественно-научного института им. П. Ф. Лесгафта (1918) до конца своей жизни Леон Абгарович возглавлял в нем отделение физиологии, где создал научные основы фризиологии двигательной активности и спортивной медицины, используемые поныне в деятельности Санкт-Петербургского университета физической культуры, спорта и здоровья. В трудные 1920-е гг., в самом начале работы в Первом Петроградском медицинском институте, он создал учение об адаптационно-трофической роли симпатической нервной системы. На базе основанной И. П. Павловым Биостанции в Колтушах создал Институт эволюционной фризиологии и патологии высшей нервной деятельности, явившийся прототипом Института эволюционной физиологии им. И. М. Сеченова АН СССР (ныне ИЭФиБ РАН). В течение 14 лет (1936 - 1950) академик $\curlywedge$. А. Орбели возглавлял Институт физиологии им. И. П. Павлова АН СССР, где способствовал взаимному обогащению двух крупных физиологических научных школ Петрограда - Ленинграда (Ленинградского университета и Института экспериментальной медицины) . Там же, а также на кафедре нормальной фризиологии Военно-медицинской академии на основе павловской концепции об анализаторах создал учение о взаимоотношениях афферентных систем.

Необоснованная и необъективная критика деятельности $\lambda$. А. Орбели как руководителя отечественной физиологии на сессии ВАСХНИЛ и на объединенной сессии АН СССР и АМН СССР в 1950 г. привела к тому, что он вынужден был уйти из большинства своих лабораторий, сосредоточив научную деятельность в физиологической лаборатории Естественно-научного института им. П. Ф. Лесгафта. Вскоре обнаружились беспочвенность и бессмысленность большинства обвинений, сделанных в адрес $\lambda$. А. Орбели, и он вернулся к активной научной и общественной деятельности в качестве консультанта Военно-медицинской академии им. С. М. Кирова и директора созданного им Института эволюционной фризиологии им. И. М. Сеченова, который он и возглавлял до последних дней своей жизни.

Заслугой $\lambda$. А. Орбели является создание теоретических предпосылок и практических основ нового раздела физиологии - физиологии труда. Впервые в России и СССР академик $\lambda$. А. Орбели создал на физиологической основе принципиально новую генерацию врачей-исследователей.

Аанная статья посвящена столетию с момента зарождения научной школы $\lambda$. А. Орбели. Эта научная школа явилась материнской по отношению к научным школам многочисленных учеников академика $\lambda$. А. Орбели.

\section{Конфликт интересов}

Автор заявия об отсутствии потенциального конфликта интересов. 


\section{Conflict of interest}

Author declares no conflict of interest.

\section{Соответствие нормам этики}

Автор подтверждает, что соблюдены права людей, принимавших участие в исследовании, включая получение информированного согласия в тех случаях, когда оно необходимо, и правила обращения с животными в случаях их использования в работе. Подробная информация содержится в Правилах для авторов.

\section{Compliance with ethical principles}

The author confirms that they respect the rights of the people participated in the study, including obtaining informed consent when it is necessary, and the rules of treatment of animals when they are used in the study. Author Guidelines contains the detailed information.

\section{ЛИТЕРАТУРА}

1. Ленинградский медицинский институт: К XXXлетию деятельности (1897-1927). - Л.: Изд. Ленингр. Мед. ин-та, 1928. - 127 с.
2. Надежкин Л. В., Коробкова С. В., Еремина А. М. Кафедра нормальной физиологии (к 100-летию основания). - СПб.: СПбГМУ, 1998. - 51 с.

3. Орбели Л. А. в воспоминаниях современников: к 100-летию со дня рождения / отв. ред. Е. М. Крепс. Л.: Наука, 1983. - 160 с.

4. Лебединский A. В., Мозжухин A. C. Очерки истории кафедры физиологии Военно-медицинской академии. Л.: Б. и., 1971. - 168 с.

\section{REFERENCES}

1. Leningradskiy medicinskiy institute: K XXX-letiyu deyatelnosti (1897-1927). Leningrad, Izdaniye Leningradskogo medicinskogo instituta, 1928:127. (In Russ.).

2. Kafedra normalnoy fiziologii (k 100-letiyu osnovaniya) / L. V. Nadezhkin a.o. SPb., Medicinskiy Universitet, 1998: 51. (In Russ.).

3. Orbeli L. A. v vospominaniyah sovremennikov: K 100-letiyu so dnya rozhdeniya / otv. red. E. M. Kreps. Leningrad, Nauka, 1983:160. (In Russ.).

4. Lebedinskiy A. V., Mozzhukhin A. S. Ocherki Istoriiy Kafedry fiziologii Voenno-Medicinskoy akademii. Leningrad, 1971:168. (In Russ.).

\section{Информация об авторе}

Колбанов Владимир Васильевич, доктор медицинских наук, профессор, профессор кафедры физиологии нормальной, Первый Санкт-Петербургский государственный медицинский университет им. акад. И. П. Павлова (Санкт-Петербург, Россия) .

\section{Information about author}

Kolbanov Vladimir V., Dr. of Sci. (Med.), Professor, Professor of the Department of Normal Physiology, Pavlov University (Saint Petersburg, Russia). 